\title{
NNEPEQ-Chemical Equilibrium Version of the Navy/NASA Engine Program
}

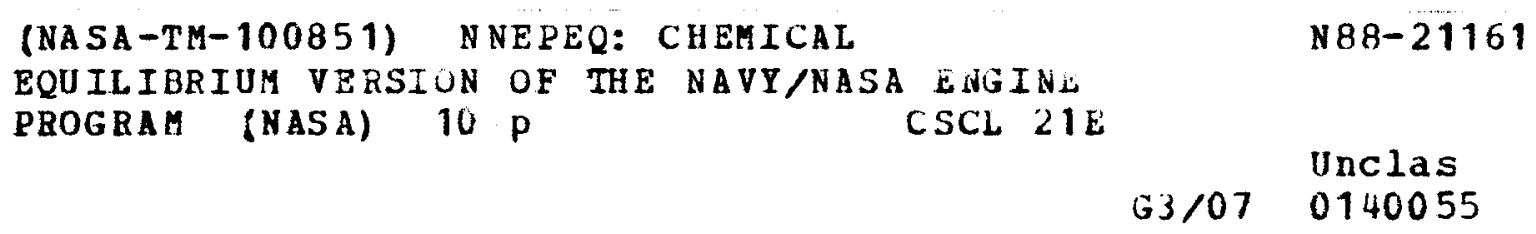

Laurence H. Fishbach

Lewis Research Center

Cleveland, Ohio

and

Sanford Gordon

Sanford Gordon \& Associates

Cleveland, Ohio

Prepared for the

1988 International Gas Turbine and Aerospace Congress

sponsored by the American Society of Mechanical Engineers

Amsterdam, The Netherlands, June 5-9, 1988 


\title{
NNEPEQ - Chemical Equilibrium Version of the Navy/NASA Engine Program
}

\author{
Laurence H. Fishbach \\ NASA Lewis Research Center \\ Cleveland, Ohio \\ and \\ Sanford Gordon \\ Sanford Gordon \& Associates \\ Cleveland, Ohio
}

\begin{abstract}
The Navy NASA Engine Program - NNEP, developed in 1975, currently is in use at a large number of government agencies, commercial companies and universities. This computer code has been used extensively to calculate the design and off-design (matched) performance of a broad range of turbine engines, ranging from subsonic turboprops to variable cycle engines for supersonic transports.

Recently, there has been increased interest in applications for which NNEP was not capable of simulating, namely, high Mach applications, alternate fuels including cryogenics, and cycles such as the gas generator air-turbo-rocket (ATR). In addition, there is interest in cycles employing ejectors such as for military fighters. New engine component models had to be created for incorporation into NNEP, and it was also found necessary to include chemical dissociation effects of high temperature gases.
\end{abstract}

This paper discusses the incorporation of these extended capabilities into NNEP and illustrates some of the effects of these changes.

\section{INTRODUCTION}

During the early 70's, NASA embarked upon the study of technology for the airframe and engines for a supersonic transport - the Supersonic Cruise Research Program SCR. Out of this program emerged a class of engines whose design/ off-design performance could not be predicted using any of the existing computational methods. The NASA Lewis Research Center embarked upon a joint program with the Naval Air Development Center to develop a computer code capable of not only simulating these engines; but also having the capability of optimizing any variable geometry setting at each operating point. The development was based upon an existing Navy program NEPCOMP (ref. 1) and was reported in reference 2. 
This new engine simulation computer program, NNEP, has gained wide acceptance and is currently in use at over 70 institutions. The NNEP computer code does not contain any preset engine cycles that the user can calculate by just issuing a command such as run turbojet, etc. Instead, it requires that the user, through a set of inputs, identify the mechanical and thermodynamic connections between the components of the engine. A block diagram is constructed to represent the engine configuration to be studied. The components of the engine can consist of any combination of inlets, ducts (burners), water injectors, compressors (fans), turbines, heat exchangers, flow splitters, mixers, and nozzles. The NNEP program logic uses flow stations and the numbers that are assigned to them to determine the flow path of gases through the engine. Herein lies the versatility of NNEP in that inputs to the code determine the engine to be simulated without the need to build in all the cycles in advance. NNEP can therefore simulate simple engines such as turbojets to highly complicated variable cycle engines with variable geometry. It uses component maps in order to calcrlate off-design performance.

However, just as NNEP was developed to address shortcomings in the previous methodologies, new areas of interest have arisen that NNEP, with all its versatility, could not handle.

The first area that could not be handled was the use of cryogenic fuels, non-hydrocarbon fuels, and the possibly high resulting temperatures where chemical dissociation of the gas stream might occur. The second area was in a class of engines where flow is introduced into the engine from a source other than an inlet. An example of this type of engine is the gas generator air-turbo-rocket. The third area involved engines incorporating ejectors such as a turbojet engine being used as the primary flow source of an ejector for an Advanced Short Takeoff and Vertical Landing (ASTOVL) aircraft.

This paper will describe the additional capabilities added to NNEP resulting in a new code NNEPEQ, which stands for the Navy NASA Engine Program with EQuilibrium effects

\section{GENERAL CHEMISTRY AND DISSOCIATION EFFECTS}

In order to extend the NNEP capability to use other than hydrocarbon fuels and to include dissociation effects that occur at high temperatures, a number of additions and modifications to NNEP were required. These consist primarily of the addition of a number of subroutines to handle chemical equilibrium calculations and a new subroutine which serves as an interface between the engine routines and the equilibrium routines.

Chemical equilibrium compositions and thermodynamic mixture properties and derivatives are obtained by means of a modified version of the general chemical equilibrium program of reference 3 (currently referred to as CET86). The CET86 program, developed 
at the NASA Lewis Research Center, has had a wide acceptance (currently used by several hundred institutions) and has been extensively tested. A number of subroutines in CET86 were eliminated (such as those for shock and detonations) and the remainder, with appropriate modifications, were added to NNEP. This new NNEP program, NNEPEQ, is capable of handling any chemical system for which thermodynamic data are available. A library of thermodynamic data, in the form of least squares coefficients required by CET86, is provided with the program.

For each component that requires reactants to be added, provision has been made for specifying up to 6 fuels and their corresponding relative fuel weights and, similarly, up to 6 oxidants and their corresponding relative oxidant weights.

An example of the effect of dissociation on calculated performance is shown in figure 1 . Shown plotted as a function of turbine inlet temperature is the percent increase due to dissociation in fuel flow, net thrust per unit airflow ( $\left.\mathrm{F} / \mathrm{W}_{\text {air }}\right)$, and total specific fuel consumption TSFC (net thrust per unit fuel flow). This example is for a 1-spool turbojet. The JP4 fuel has a lower heat of combustion of $18,300 \mathrm{Btu} / \mathrm{lb}$ and a combustion efficiency of 0.995 . Computer runs were made for burner-out temperatures in the range of 2260 to $4540{ }^{\circ} \mathrm{R}$. As may be seen in figure 1 , dissociation effects are negligible below about $2300^{\circ} \mathrm{R}$. However, at $4540^{\circ} \mathrm{R}$ (the stoichiometric temperature), dissociation causes an increase of $11.1 \%$ in fuel flow, a $6.4 \%$ increase in $\mathrm{F} / \mathrm{W}_{\mathrm{air}}$, and a $4.4 \%$ increase in TSFC.

The increase in fuel is due to the higher energy requirements to heat a dissociating gas to a specified temperature. This also results in an increase in the thrust per unit airflow as follows. The increase in fuel increases the mass flow in the engine. This results in an increase in $\mathrm{F} / \mathrm{W}$ air of $0.6 \%$. However, the recombination of the combustion products results in an increase in nozzle total temperature which therefore yields an increase in jet velocity. This results in an additional increase in $\mathrm{F} / \mathrm{W}_{\text {air }}$ giving the total shown of $6 \%$. Thus, approximately $10 \%$ of the increase is due to additional fuel, and $90 \%$ due to recombination.

When no dissociation is considered, as in NNEP, the determination of the composition of combustion products is based on mass balance considerations only and is rather trivial. By contrast, the determination of equilibrium compositions, as in NNEPEQ, involves solving non-linear sets of equations which generally requires an iteration process. It is not surprising, therefore, that NNEPEQ requires considerably more computer time than NNEP. As an example, computer runs were made on an IBM 370 computer for ten different configurations of a 1-spool mixed flow turbofan. The configurations involved both on-design and off-design modes. The total CPU time for NNEP was only 4 seconds as contrasted with 93 seconds for NNEPEQ - a factor of about 24. Work is currently in progress to shorten the NNEPEQ running time by use of several techniques to reduce the number of iterations required for convergence. 


\section{GAS GENERATORS}

As previously mentioned, the need arose to be able to simulate engine cycles where gas was introduced into the engine other than as flow through an inlet or as fuel in a burner. A typical example of this is the air-turbo-rocket (ATR) shown in figure 2. In this engine, air enters the inlet and then passes through a compressor raising both the pressure and temperature. At high Mach number or high pressure ratio, this temperature may be so high that little or no energy can be added by buming fuel without exceeding turbine inlet temperature limits. Therefore, the compressor discharge air does not pass through the turbine - it is ducted around it. Instead, a gas generator is added to the engine. Reactants, such as hydrogen and oxygen, are mixed together and ignited to some temperature less than the allowable turbine inlet temperature. The resulting high temperature and pressure gas is then expanded through the turbine which is connected through a shaft to the compressor. The exhaust products of the turbine are then mixed with the air ducted around the turbine and, if desired, more fuel added and burned in an afterburner. This engine has been proposed for operation at Mach numbers as high as five with the turbomachinery still running.

NNEPEQ does not run preconfigured engine cycles and the user, through inputs, connects the components together. The solution to simulating an ATR is to introduce the gas generator component anywhere the user might desire it in the engine cycle. Ablock diagram is drawn, such as in figures 3 and 4, representing the components of the engine. The flow stations that are identified at the entrance and exit of each component (shown in figures 3 and 4 as encircled numbers) are then used to construct the gas flow path through the engine. As an example, if the exit flow station number for the inlet of the engine has a value of 2, the next component in the path would be that one that had 2 as the entering station number, etc.

There is only one method available in NNEPEQ to identify multiple gas flow paths in an engine cycle - the use of a splitter. A splitter divides the flow into two streams, a primary and a secondary. The logic in NNEPEQ forces the cycle calculations to proceed along the primary path until either a mixer or a nozzle occurs. When either of these components appears, the program goes back to see if there are any splitters from which the secondary flow path has not been followed or completed. As is the case for the primary flow, the secondary flow must terminate either in a mixer or a second nozzle. Thus, the use of a splitter provided the key to simulating the ATR cycle.

A NNEPEQ schematic of the ATR cycle (Fig. 2) is shown in figure 3. The location of the splitter can be either before or after the compressor. For the cycle shown, air enters the inlet, is compressed, and split into two streams. The primary path air then enters the mixer. Logical coding in NNEPEQ detects the mixer component and looks upstream for a splitter, which of course it finds. The NNEPEQ program logic then follows the splitter secondary path at station 5 into the new gas generator component (GGEN). For this special case, there is no 
flow at station 5 because the user sets the splitter input specification for this path to zero. Zero flow at station 5 does not interfere with the NNEPEQ program logic. Inputs to the gas generator define the fuel(s) and oxidizer(s) being reacted and their mass flows. In this way, the GGEN component becomes a source of gas flow coming from the splitter secondary outlet and proceeding on to the turbine entrance at station 6 .

When generator temperature is specified, the program will determine the corresponding $\mathrm{f} / \mathrm{o}$ ratio by an iteration process. Other options are available for input to the generator, such as specifying the $\mathrm{f} / \mathrm{o}$ weight ratio rather than the generator temperature. When $\mathrm{f} / \mathrm{o}$ is specified, the program will calculate the corresponding generator temperature.

\section{EJECTORS}

As mentioned in the INTRODUCTION, interest has arisen in a class of engines incorporating ejectors. An example of this is shown in figure 4. This engine is of interest for one version of an ASTOVL aircraft. Compressor discharge air is ducted forward to an ejector while the rest of the compressor air proceeds on back through the main nozzle. The ejector primary air induces additional secondary flow through another inlet and is exhausted vertically towards the front of the vehicle. The main flow is canted slightly downward at the rear of the vehicle. These two exhaust streams are used to provide the short takeoff.

The MIXER component subroutine contained in NNEP was readily modified to simulate an ejector. Referring to figure 4, the ejector is shown as the MIXR (component 8).The two flow streams entering the ejector are the primary flow (station 5) which consists of the high pressure air from the compressor discharge (station 3 from component 2), and the ejector secondary flow from the ramjet inlet (station 10 from component 7 ). The computer code was changed so that an indicator can be set in the input to show that an ejector is being simulated. Another indicator is set to specify whether subsonic or supersonic (2nd solution) exit conditions from the mixer exist. The momentum recovery coefficient for both streams, ejector primary exit Mach number, area ratio for the ejector, and primary flow injection angle are all specified.

The continuity, momentum and energy equations are solved simultaneously for the ejector control volume, and the mixed velocity is obtained. Cycle calculations then proceed on through the remainder of the engine.

\section{CONCLUDING REMARKS}

The advanced aircraft and their powerplants envisioned for the next century represent an enormous challenge to the engineering community. Significant advances in both materials and fuels are being projected in order to achieve the high temperatures needed to develop efficient powerplants and vehicles. These high temperatures have presented a challenge to 
the existing computational methods of predicting engine performance because of the dissociation effects that must be taken into account. The engine cycles envisioned for these vehicles also present a challenge.

The new version of NNEP reported herein, has proven capable of meeting these challenges. NNEPEQ can simulate most, if not all, of these engine cycles; be used to study the effects of different fuel types such as cryogenics or slurries; and last, but not least, account for the effects of dissociation at the high temperatures of these cycles. It is believed that NNEPEQ will prove to be even more valuable as a study tool than its predecessor.

\section{ACKNOWLEDGEMENT}

The authors wish to thank the members of the Advanced Planning and Analysis Office of the NASA Lewis Research Center. Their assistance was invaluable in debugging and testing of the many versions of NNEPEQ which led to the final product.

\section{REFERENCES}

1. Caddy, Michael J.; and Shapiro, Stanley R.: NEPCOMP - The Navy Engine Performance Computer Program, Version I. NADC - 74045 - 30, 1975.

2. Fishbach, Laurence H.; and Caddy, Michael J.: NNEP - The Navy NASA Engine Program. NASA TM X-71857, 1975.

3. Gordon, Sanford; and McBride, Bonnie J.: Computer Program for Calculation of Complex Chemical Equilibrium Compositions, Rocket Performance, Incident and Reflected Shocks, and Chapman-Jouguet Detonations. NASA SP-273, 1976. 


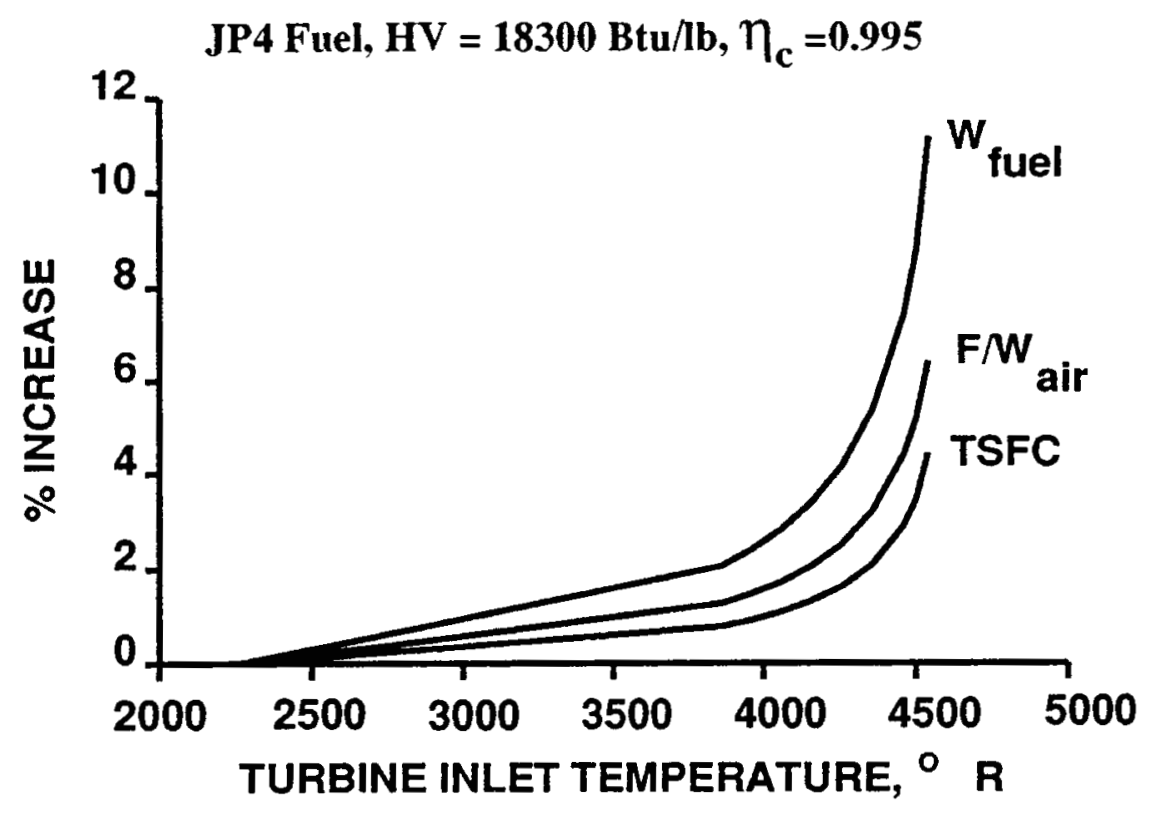

Fig. 1 Effects of Dissociation on Engine Performance

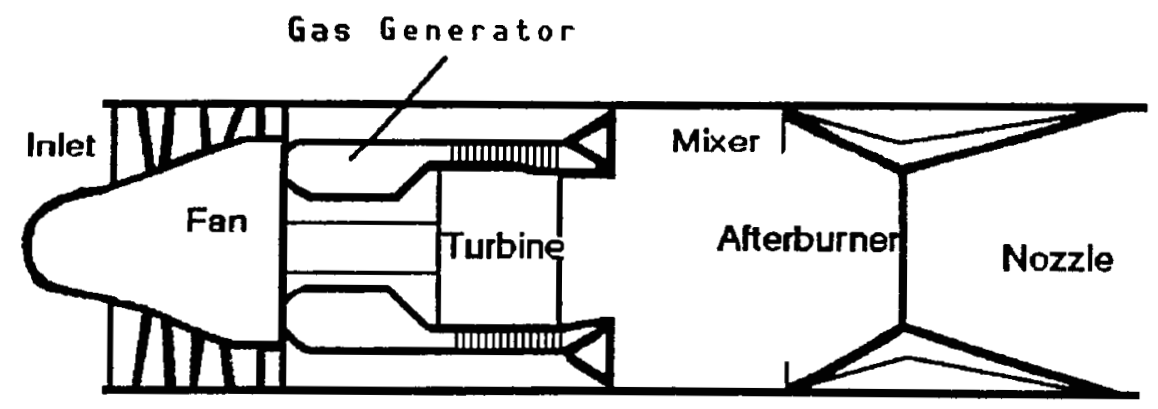

Fig. 2 Schematic of Gas Generator Air-Turbo-Rocket (ATR) 


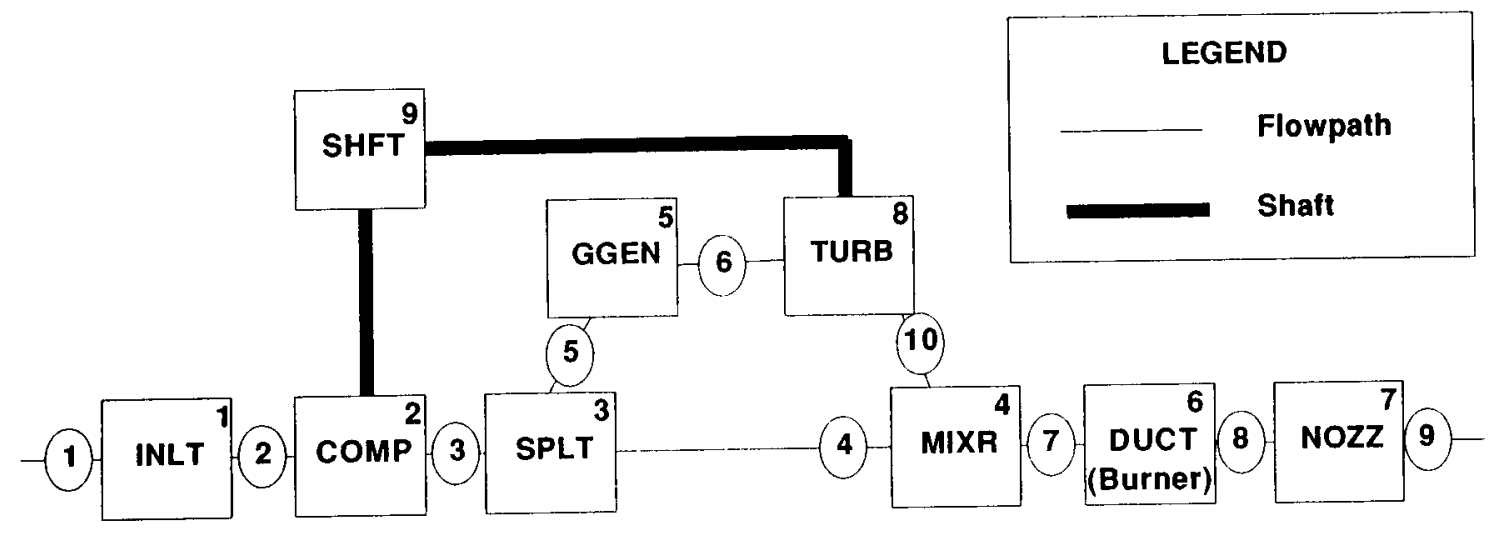

Fig. 3 NNEPEQ Schematic of Gas Generator ATR

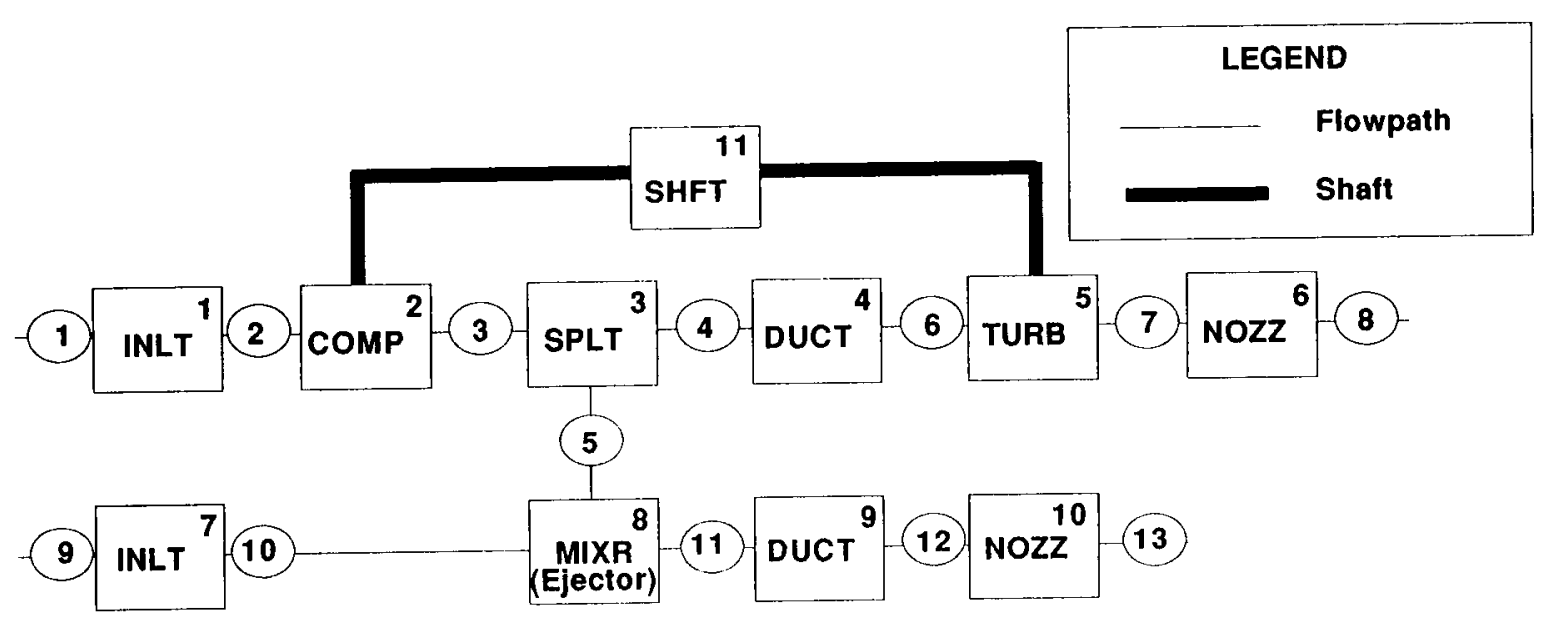

Fig. 4 NNEPEQ Schematic of Propulsion System for Ejector ASTOVL Aircraft 


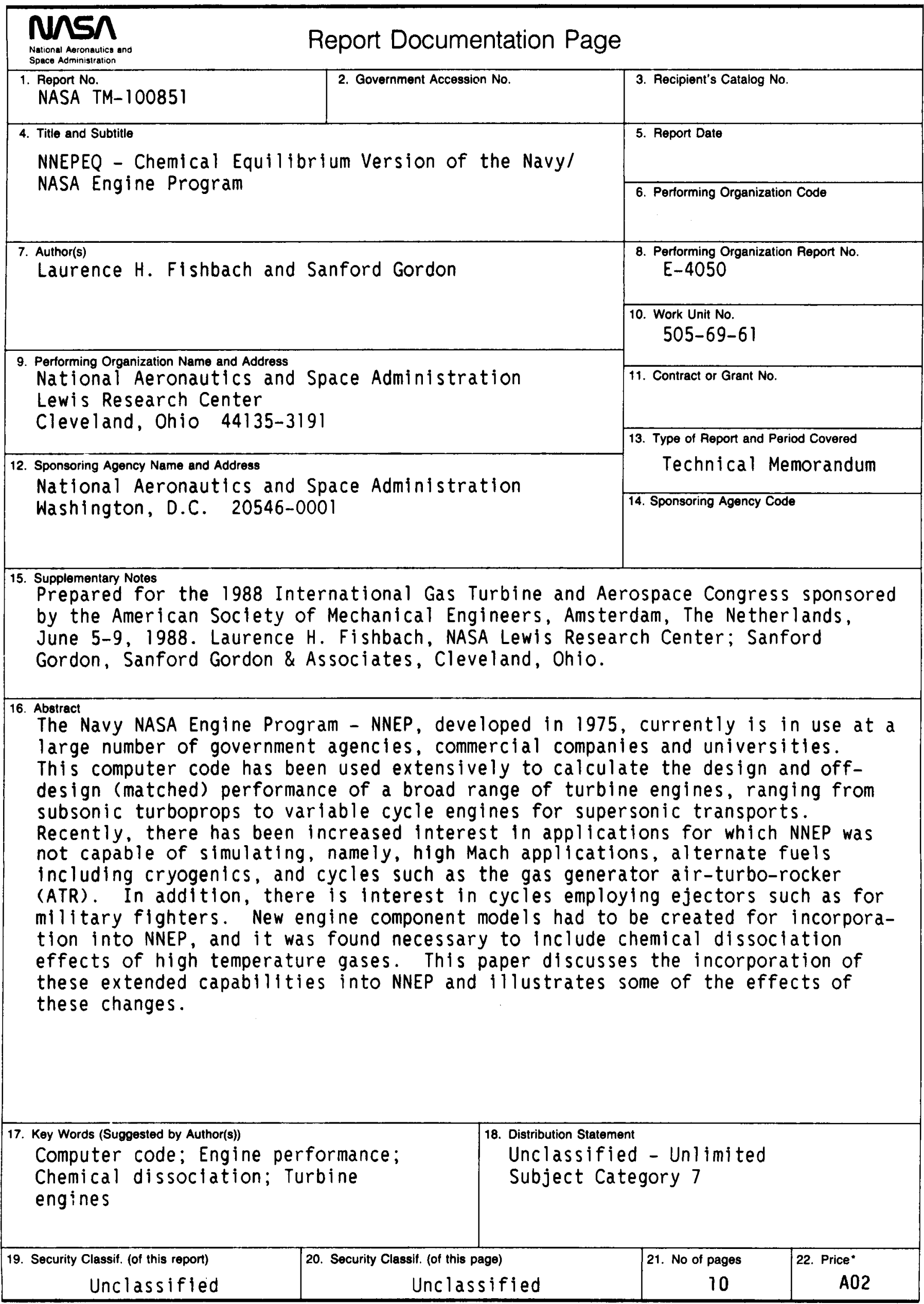

NASA FOAm 1628 OCT $86 \quad$ "For sale by the National Technical Information Service, Springfield, Virginia 22161 